\title{
Respiratory symptoms of rural Fijian and Indian children in Fiji
}

\author{
M G L Flynn
}

\begin{abstract}
Background - Significant ethnic differences exist in the respiratory morbidity of children in the Fiji Islands. Indian children have higher national hospital admission rates for asthma whereas Fijian children have higher admission rates for pneumonia. In Suva City the prevalence of wheeze is similar in Fijian and Indian children, productive cough is more common in Fijians, and bronchial hyperresponsiveness is more common in Indians. This study was undertaken to see whether ethnic differences in national hospital admission rates are reflected in the prevalence of respiratory symptoms in rural children.
\end{abstract}

Methods - A respiratory symptoms questionnaire in three languages with known repeatability was returned by $487(98 \cdot 2 \%)$ of 496 class 4 primary school children with a mean age of 9.3 years living in Nausori District, an agrarian region with a climate similar to Suva City.

Results - The prevalence of one or more episodes of wheezing in the last 12 months was similar in Fijians (19.8\%) and Indians (19.4\%). However, 8.9\% of Indian children had experienced four or more episodes of wheeze in the last 12 months compared with only $2.9 \%$ of Fijian children. Productive cough on most mornings occurred more frequently in Fijians (35.8\%) than Indians $(23.9 \%)$, but this difference was not significant after controlling for the presence of a smoker in the home.

Conclusions - This study provides the first evidence that frequent wheeze (four or more episodes in the last 12 months) is more prevalent in Indian than Fijian children. The higher prevalence of productive cough in Fijian children may be related to exposure to smoking in the home.

(Thorax 1994;49:1201-1204)

Previous work in Fiji has shown that hospital admission rates for asthma in Indian children in the 5-14 year age groups are three times higher than in Fijians. ${ }^{1}$ A study of urban schoolchildren in Suva City found that the prevalence of wheeze in the previous 12 months was identical in both ethnic groups ( $21 \%)$, but bronchial hyperresponsiveness was twice as common in Indians $(30 \%)$ as in Fijians (15\%). The combination of current wheeze and bronchial hyperresponsiveness occurred nearly three times more often in Indian children $(11.3 \%)$ than in Fijians $(4.0 \%)$, and the mean bronchial dose- response slope to histamine was steeper in Indians than Fijians. ${ }^{2}$ These findings suggest that Indian children may have more severe asthma than Fijian children.

By contrast, hospital admission rates for pneumonia in Fijian children are three times higher than in Indian children. ${ }^{1}$ The prevalence of productive cough on most mornings in urban Fijian schoolchildren is nearly twice that of Indian schoolchildren and increases with domestic crowding. ${ }^{2}$

This study was undertaken to see whether ethnic differences in national hospital admission rates are reflected in the prevalence of respiratory symptoms in rural Fijian and Indian children.

\section{Methods}

The children chosen for study were the class 4 pupils of all rural primary schools in the lower Rewa Valley in the Nausori Education District of the main island of Viti Levu. This is an agrarian region with a climate similar to Suva City. Urban schools in Nausori Town were excluded. Sample size was sufficient to detect a twofold ethnic difference with a confidence level of $95 \%$ and a power of $80 \%$ given symptom prevalences of $10-30 \%$.

A respiratory symptoms questionnaire in three languages was distributed in May 1991 for completion by parents. A second distribution occurred the following week for children who were absent on the first occasion or had not returned the questionnaire. The questionnaire and measures of its repeatability have been described previously. ${ }^{2}$ It includes items concerning symptoms and physician-diagnosed asthma (table), subdivision of birth, the presence of tobacco smoking in the home, cooking fuel, domestic crowding (measured as the number of people sleeping in the child's room), type of dwelling, and the relationship to the child of the person answering the questionnaire. The child's ethnicity was determined from that of both parents. Question 9 ("Has this child ever had a cough?") attempted to detect attitudinal bias - that is, the possible tendency of one ethnic group to systematically report more "yes" answers than another."

Data were entered into a computer and analysed with SPSS/PC + version 3.1 (SPSS Inc, Chicago, USA). The $\chi^{2}$ statistic for analysis of contingency tables with Yates's correction for continuity was used to test for associations of categorical variables. The influence of age was analysed in two groups: children under 9.5 years ("nine year olds"), and children over 9.5 years ("ten year olds"). Confidence intervals for 
Prevalence of symptoms and diagnosed asthma in Nausori

\begin{tabular}{|c|c|c|c|}
\hline \multirow[t]{2}{*}{ Question } & \multicolumn{3}{|c|}{ Prevalence \% (95\% confidence interval) } \\
\hline & $\begin{array}{l}\text { Fijians } \\
(n=208)\end{array}$ & $\begin{array}{l}\text { Indians } \\
(n=249)\end{array}$ & $\begin{array}{l}\text { All groups } \\
(n=487)\end{array}$ \\
\hline \multirow{5}{*}{$\begin{array}{l}\text { (4) Wheeze ever } \\
\text { (5) Wheeze in last } 12 \text { months* } \\
1-3 \text { times } \\
4-12 \text { times } \\
>12 \text { times } \\
\text { total } \\
\text { (6) Woken by dyspnoea in last } \\
12 \text { months } \\
\text { (7) Dry cough at night in last } \\
12 \text { months } \\
\text { (8) Coughed mucus most } \\
\text { mornings in the last } 12 \text { monthst } \\
\text { (10) Doctor-diagnosed asthma }\end{array}$} & $21 \cdot 8(16 \cdot 2$ to $27 \cdot 4)$ & $20 \cdot 2(15 \cdot 2$ to $25 \cdot 2)$ & $20 \cdot 7(17 \cdot 1$ to $24 \cdot 3)$ \\
\hline & $\begin{array}{r}16.9 \\
1.4 \\
1.4 \\
19.8(14.4 \text { to } 25 \cdot 2) \\
13.3(8.7 \text { to } 17.9)\end{array}$ & $\begin{array}{l}10 \cdot 5 \\
4 \cdot 8 \\
4 \cdot 0 \\
19 \cdot 4(14 \cdot 5 \text { to } 24 \cdot 3) \\
13 \cdot 6(9 \cdot 3 \text { to } 17 \cdot 9)\end{array}$ & $\begin{array}{l}14 \cdot 1 \\
3 \cdot 3 \\
2 \cdot 7 \\
20 \cdot 1(16 \cdot 5 \text { to } 23 \cdot 7) \\
13 \cdot 8(10 \cdot 7 \text { to } 16 \cdot 9)\end{array}$ \\
\hline & $34 \cdot 0(27 \cdot 6$ to $40 \cdot 4)$ & $38 \cdot 8(32 \cdot 7$ to $44 \cdot 9)$ & $36.9(32.6$ to $41 \cdot 2)$ \\
\hline & $35 \cdot 8(29.3$ to $42 \cdot 3)$ & $23.9(18.6$ to $29 \cdot 2)$ & $30.0(25.9$ to $34 \cdot 1)$ \\
\hline & $6.5(3.1$ to 9.9$)$ & $8 \cdot 3(4.9$ to $11 \cdot 7)$ & $7 \cdot 3(5.0$ to $9 \cdot 6)$ \\
\hline
\end{tabular}

${ }^{*} p=0.02,+p<0.01$, comparison of Fijians with Indians.

proportion were obtained by using the Normal approximation to the binomial distribution. ${ }^{4}$ The $\chi^{2}$ for trend (Mantel extension) was used to test for trend in prevalence of each symptom or asthma diagnosis over increasing levels of domestic crowding. Stratified analysis with the Mantel-Haenszel procedure was used to examine potential confounding variables (Epi Info version 5.00, Centers for Disease Control, Atlanta, Georgia, USA).

The study was approved by the joint ethics committee of the Colonial War Memorial Hospital and Fiji School of Medicine.

\section{Results}

There were 496 children on the class enrolment lists of whom $487(98 \cdot 2 \%)$ returned the questionnaire. Completion rates for individual items in the returned questionnaires were $95 \%$ or higher, except for questions about asthma in the father $(89 \%)$ or mother $(90 \%)$, and the question about cooking fuel (87\%). Fijians were somewhat older (mean (SD) $9.5(0.8)$ years) than Indians $(9.0(0.5)$ years). There were 208 Fijian children (105 boys, 103 girls), 249 Indians ( 129 boys, 120 girls), 15 children of mixed or other ethnicity, and 15 with incomplete ethnic data.

The prevalence of respiratory symptoms is shown in the table. The prevalence of "wheeze ever" was very similar in both ethnic groups. The question about "wheeze in the last 12 months" offered four categories of response: none; 1-3 times; 4-12 times; >12 times. Contingency table analysis of these four categories found a significant ethnic difference $\left(\chi^{2}=10\right.$, $p=0.02)$. This difference lay not in the overall prevalence of wheeze in the past 12 months (Fijians $19 \cdot 8 \%$, Indians $19 \cdot 4 \%$ ), but in the frequency of episodes. Four or more episodes of wheeze ("frequent wheeze") occurred in $8.9 \%$ of all Indian children compared with $2.9 \%$ of all Fijian children $\left(\chi^{2}=6 \cdot 0, p=0.01\right)$.

Productive cough occurred significantly more frequently in Fijians $(35.8 \%)$ than Indians $\left(23.9 \%, \chi^{2}=6.9, p<0.01\right)$. The prevalences of other symptoms and of physiciandiagnosed asthma were similar in Fijians and Indians.

Productive cough was more common in children with a smoker in the home $(39.7 \%)$ compared with those without a smoker in the home $\left(19.5 \% ; \chi^{2}=21, p<0.0001\right)$. Smokers were more common in the homes of Fijian children (69\%) than Indians (37\%), and the higher prevalence of productive cough in Fijians was not statistically significant when the MantelHaenszel procedure was used to examine the confounding effect of a smoker in the home. Other respiratory symptoms and a history of asthma diagnosis were not associated with the presence of a smoker.

Each of the symptoms, as well as diagnosed asthma, occurred more frequently in children with a parental history of asthma. There was no significant association between any respiratory symptom or asthma diagnosis with subdivision of birth, age group, gender, domestic crowding, cooking fuel, or type of dwelling. The two symptoms associated with ethnicity ("wheeze in the last 12 months" and "productive cough") were not associated with the relationship to the child of the person answering the questionnaire.

The question used to check for attitudinal bias ("cough ever") elicited an affirmative response more often in Fijians (90\%) than Indians $\left(81 \%, \chi^{2}=6 \cdot 6, p=0 \cdot 01\right)$. This difference remained significant when analysis was confined to children whose parents answered "no" to all respiratory symptoms including both cough symptoms (Fijians $83 \%$, Indians $69 \%$, $\left.\chi^{2}=4.6, p<0.05\right)$. When attitudinal bias was controlled by restricting analysis to those children whose parents answered "yes" to "cough ever", the ethnic pattern of symptom prevalence was not substantially altered: frequent wheeze occurred in $10.7 \%$ of Indians compared with $3.2 \%$ of Fijians $\left(\chi^{2}=6.9, p<0.01\right)$, while productive cough was found in $38.3 \%$ of Fijians compared with $29.5 \%$ of Indians $\left(\chi^{2}=2 \cdot 8\right.$, $\mathrm{p}>0 \cdot 05$ ).

The commonest language of completion was English (59\%), followed by Fijian (36\%), and Hindi (3\%), with the remaining $2 \%$ completed in two languages. Only 33 of 208 Fijian children returned questionnaires in English, so it was not possible to control satisfactorily for the potential bias due to language. However, the trends in symptom prevalence were unchanged: frequent wheeze occurred in $9.5 \%(22 / 231)$ of Indian children compared with $0 \%(0 / 33)$ of Fijian children; productive cough occurred in $30 \cdot 3 \%(10 / 33)$ of Fijians compared with $24 \cdot 0 \%$ $(53 / 221)$ of Indians.

\section{Discussion}

This study found that, while the overall prevalence of wheeze in Fijian and Indian children is similar, frequent wheeze occurs three times more often in Indians than Fijians. This finding is important because it is the first evidence of a difference in the severity of asthma symptoms in Fijian and Indian children, being consistent with the higher national hospital admission rates for asthma in Indians, ${ }^{1}$ and the greater prevalence of bronchial hyperresponsiveness found in Indian children in Suva City. ${ }^{2}$ In Suva City the ethnic differences in frequency of wheeze in the last 12 months were minor and not statistically significant, even though frequency of wheeze was significantly associated with the severity of bronchial hyperresponsiveness. $^{2}$ 
Indian children may have more severe asthma, and hence more frequent wheeze, than Fijians because of either genetic or environmental factors. There is evidence of genetic predisposition for atopy, ${ }^{5}$ asthma,${ }^{6}$ and, possibly, bronchial hyperresponsiveness. Atopy was not assessed in this study and cannot be excluded as a factor in the ethnic difference in frequency of wheeze. A study of urban children found Fijians and Indians to have a similar prevalence of atopy to a range of allergens. ${ }^{2}$ The higher level of bronchial responsiveness in Indians might be explained by higher dietary salt ${ }^{89}$ or the absence of fish from the diet of vegetarians. ${ }^{111}$

This study also found that, in contrast to frequent wheeze, productive cough was more common in Fijians than Indians. However, productive cough was significantly associated with the presence of a smoker in the child's home, and the higher prevalence of productive cough in Fijians was not statistically significant when the Mantel-Haenszel procedure was used to examine the confounding effect of a smoker in the home. Schenker $e t a l^{12}$ found that parental smoking was significantly associated with chest illness in the past year among 5-14 year olds, but not with productive cough or persistent wheeze.

Fijian children have a higher hospital admission rate for pneumonia, ${ }^{1}$ and it may be that both passive smoking and respiratory infection are involved in the higher prevalence of productive cough. Productive cough has been associated with domestic crowding in $\mathrm{Fiji}^{2}{ }^{2}$ and has been thought to be primarily determined by respiratory infection in Papua New Guinea. ${ }^{13}$ Purulent nasal discharge in the children of developing countries has been attributed to higher nasal carriage rates of bacterial pathogens. ${ }^{14}$ Indoor biofuel smoke has been linked with acute respiratory infection ${ }^{15}$ and the use of wood burning stoves for indoor heating with respiratory symptoms ${ }^{16}$ in young children. However, Tuthill found no association between wood stoves and respiratory symptoms in school age children. ${ }^{17}$ Asthma may also be expected to contribute to the prevalence of productive cough.

In any study which involves different ethnic groups or the use of questionnaires in more than one language there is potential for bias of cultural or linguistic origin. Using symptom diaries, West and Harris ${ }^{18}$ found that symptom prevalence declined over time most rapidly in Pacific Islanders, least rapidly in Europeans, and at an intermediate rate in Maoris. Mitchell ${ }^{3}$ examined marginals of contingency tables from studies conducted in Malaysia and found that the Chinese had a much higher proportion of "no" answers to precoded questions and fewer answers to open-ended questions than the Indians. The present study included a type of question which, to the author's knowledge, has not previously been used in respiratory questionnaires: "Has this child ever had a cough?" Since all children will have experienced cough due to infection, a major ethnic difference in affirmative responses to this question would suggest an ethnic difference in readiness to report symptoms. Although Fijians answered "yes" to this question more often than Indians, the majority of both groups did make an affirmative response and the ethnic comparisons are not substantially altered when analysis is restricted to those children with an affirmative answer. Nevertheless, an ethnic difference in questionnaire responses due to reporting attitude or literacy cannot be excluded. Such factors may explain why an ethnic difference in frequency of wheeze was found in this rural sample but not in Suva.

Access to medical care might influence the prevalence of diagnosed asthma; however, a recent analysis of outpatient attendances and hospital beds found no evidence of an ethnic difference. ${ }^{1}$

The main limitation in this study is that the questionnaire was designed to obtain basic data on symptom prevalence with only the question on frequency of wheeze being about severity. It is perhaps surprising that an ethnic difference in asthma severity is not reflected in the prevalence of dyspnoea, dry nocturnal cough, and diagnosed asthma. However, it may be that questions which allow only a "yes" or "no" response have poor sensitivity to differences in asthma severity. Future studies will need to address the issue of asthma severity in these populations in more detail.

In summary, Fijian and Indian children have a similar prevalence of wheeze and diagnosed asthma, but frequent wheeze occurs more often in Indian than Fijian children. This is consistent with previous observations that Indian children are admitted to hospital with asthma more often and have greater bronchial responsiveness to histamine than Fijian children. Asthma appears to be more severe in Indians than Fijians. By contrast, Fijian children have a greater prevalence of productive cough than Indians. This is associated with a greater exposure to smoking in the home, and may also be related to the higher hospital admission rate for pneumonia in Fijians.

The study was supported by the Health Research Council of New Zealand, and the author's appointment to the Fiji School of Medicine was supported in part by the Australian International Development Assistance Bureau.

The approval of the Permanent Secretary for Health, Republic of Fiji, is gratefully acknowledged. The author also thanks staff of the Royal Children's Hospital Melbourne and the Department of Paediatrics, University of Melbourne: Dr Terry Nolan for of Paediatrics, University of Melbourne: Dr Terry Nolan for
statistical advice, and Professor Peter Phelan for critical review.

1 Flynn MGL. Hospital admission rates for asthma and pneumonia in Fijian and Indian children. $\mathcal{f}$ Paediatr Child Health 1994;30:19-22.

2 Flynn MGL. Respiratory symptoms, bronchial responsiveness and atopy in Fijian and Indian children. $\mathrm{Am}$ 于 Respir Crit Care Med 1994;150:415-20.

3 Mitchell RE. Survey materials collected in the developing countries: sampling, measurement, and interviewing obscountries: sampling, measurement, and interviewing obstacles to intra- and inte

4 Altman DG. Practical statistics for medical research. London: Chapman and Hall, 1991:230.

5 Marsh DG, Meyers DA, Bias WB. The epidemiology and genetics of atopic allergy. $N$ Engl $\mathcal{F}$ Med $1981 ; 305: 1551-9$

6 Edfors-Lubs ML. Allergy in 7000 twin pairs. Acta Allengo 1971;26:249-85.

7 Townley RG, Bewtra A, Wilson AF, Hopp RJ, Elston RC, Nair N, et al. Segregation analysis of bronchial response to methacholine inhalation challenge in families with and

8 without asthma. F Allergy Clin Immunol 1986;77:101-7. Burney PGJ, Britton JR, Chinn S, Tattersfield AE, Plat HS, Papacosta AO, et al. Response to inhaled histamine
and 24 hour sodium excretion. $B M \mathcal{F}$ 1986;292:1483-6. 
9 Taylor R, Zimmet P, Levy S, Collins V. Group comparisons of blood pressure and indices of obesity and salt intake in

10 Peat JK, Salome CM, Woolcock AJ. Factors associated with bronchial hyperresponsiveness in Australian adults and children. Eur Respir f 1992;5:921-9.

11 Jansen AAJ. Fish consumption. In: Jansen AAJ, Parkinson S, Robertson AFS, eds. Food and nutrition in Fiji: a historical review. Volume 1. Suva, Fiji: Department of Nutrition and Dietetics of the Fiji School of Medicine and The Institute of Pacific Studies of The University of the South Pacific, 1990:451-71.

12 Schenker MB, Samet JM, Speizer FE. Risk factors for childhood respiratory disease: the effect of host factors and home environment. Am Rev Respir Dis 1983;128: and home

13 Anderson HR. Respiratory abnormalities in Papua-New
Guinea: the effect of locality and domestic wood smoke. Int 9 Epidemiol 1978;7:63-72.

14 Stansfield SK. Acute respiratory infections in the developing world: strategies for prevention, treatment and control. Pediatr Infect Dis 1987;6:622-9.

15 Pandey MR, Boleij JSM, Smith KR, Wafula EM. Indoor air pollution in developing countries and acute respiratory infection in children. Lancet 1989;i:427-9.

16 Honicky RE, Osborne JS, Akpom CA. Symptoms of respiratory illness in young children and the use of woodburning stoves for indoor heating. Pediatrics 1985;75:58793.

17 Tuthill RW. Woodstoves, formaldehyde, and respiratory disease. Am $\mathcal{F}$ Epidemiol 1984;120:952-5.

18 West SR, Harris BJ. The effect of personal characteristics on response levels in a health survey. NZ Med $\mathcal{F} 1983 ; 96$ : 666-8. 